\title{
Depressed Cardiac Contractility and Its Postnatal Development in Rats after Chemical Sympathectomy
}

\author{
J. ŠVÍGLEROVÁ, J. KUNCOVÁ, L. NALOS, J. SLAVÍKOVÁ, M. ŠTENGL \\ Department of Physiology, Faculty of Medicine in Plzeň, Charles University, Plzeň, Czech \\ Republic
}

Received February 23, 2007

Accepted June 25, 2007

On-line July 26, 2007

\section{Summary}

The contribution of the sympathetic innervation to the postnatal development of cardiac contractility remains unclear. In this study, the postnatal maturation of cardiac contractility was compared in control rats and rats after chemical sympathectomy. The chemical sympathectomy was induced by administration of 6-hydroxydopamine to newborn rats. At days 20, 40 and 60 of postnatal life, the contractile parameters and concentrations of sympathetic neurotransmitters were measured in both right and left ventricles. In rats with chemical sympathectomy, concentrations of norepinephrine were reduced almost completely in both ventricles at all time points. The contractility of the left ventricle papillary muscles was substantially decreased at all time points. In contrast, the contractility of the right ventricle papillary muscles was decreased only transiently, showing a recovery at day 60 regardless of the permanently decreased concentration of norepinephrine. The concentration of neuropeptide $Y$, another neurotransmitter present in sympathetic nerves, showed the same developmental trend as contractility: permanent reduction in the left ventricle, transient reduction with a recovery at day 60 in the right ventricle. The data indicate that the sympathetic nervous system plays an important role in the postnatal development of cardiac contractility and neuropeptide $Y$ may contribute to this effect.

\section{Key words}

Chemical sympathectomy - Contraction - Neuropeptide $\mathrm{Y}$ • Norepinephrine • Rat heart

\section{Corresponding author}

M. Štengl, Department of Physiology, Faculty of Medicine in Plzeň, Charles University, Lidická 1, 30167 Plzeň, Czech Republic. Fax: +420 377593349. E-mail: milan.stengl@lfp.cuni.cz

\section{Introduction}

The postnatal development of cardiac contractility is rather complex. In general, the contractile performance of mammalian heart increases and this improvement is due to various processes such as maturation of excitation-contraction coupling with changes in expression of sarcolemmal and reticular $\mathrm{Ca}^{2+}$ channels and transporters (Tanaka and Shigenobu 1989, Wibo et al. 1991), changes at the level of contractile proteins, their isoforms and binding properties (McAuliffe et al. 1990, Martin et al. 1991) and/or development of autonomic innervation (Robinson 1996). Autonomic (sympathetic or parasympathetic) innervation influences virtually all aspects of cardiac contractility, on both short-term and long-term basis. The short-term control is usually exerted through changes in phosphorylation of $\mathrm{Ca}^{2+}$ transporters and/or of contractile proteins (Kameyama et al. 1986), the long-term control involves changes in expression levels of these proteins (Ogawa et al. 1992, Maki et al. 1996, Protas and Robinson 1999).

The link between sympathetic innervation and contractile postnatal development was first suggested on the basis of in vitro studies, in which isolated neonatal rat myocytes were either exposed to norepinephrine (Maki et al. 1996) or co-cultured with sympathetic neurons (Ogawa et al. 1992, Protas and Robinson 1999). In such myocytes the contractile response was increased, which was attributed to the increased number of L-type $\mathrm{Ca}^{2+}$ current ( $\mathrm{ICaL}$ ) channels. The above studies, however, raise question, what is the actual trophic factor underlying the increase in ICaL. Increase in dihydropyridine receptor 
expression after exposure to norepinephrine (Maki et al. 1996) clearly favors norepinephrine. However, Protas and Robinson (1999) indicated that the sympathetic innervation contributes to the developmental ICaL increase through neurally released neuropeptide $\mathrm{Y}$ (NPY), which is stored in most sympathetic nerves as a cotransmitter with norepinephrine (Zukowska et al. 2003). The question, whether the sympathetic innervation indeed contributes to contractility improvement in vivo, is less clear and compelling evidence is lacking. Recently, Protas et al. (2003) addressed this question using transgenic NPY-deficient mice and their results suggest that also in vivo NPY contributes to the postnatal increase in ICaL.

To elucidate whether norepinephrine and/or NPY contribute to the postnatal development of contractility, we have performed experiments in rats with chemical sympathectomy induced by the administration of 6-hydroxydopamine (6-OHDA). Norepinephrine and NPY levels were measured at 20, 40 and 60 days of postnatal life and correlated with contraction force measurements in both right and left ventricle papillary muscles. The data show a differential response of the right and left ventricles to the sympathectomy and suggest an important role for NPY in regulation of postnatal contractility development.

\section{Methods}

All experiments were conducted in accordance with European Directive for the Protection of Vertebrate Animals Used for Experimental and Other Scientific Purposes (86/609/EU), the relevant Guidelines of the Czech Ministry of Agriculture for scientific experimentation on animals and were approved by the University Committee for Experiments on Laboratory Animals (Charles University, Czech Republic).

\section{Animals}

A total of 180 newborn Wistar rats were used. Pups were randomly divided into two groups on the day of birth, designated as postnatal day 0 . The first group (6-OHDA) received subcutaneously 6-hydroxydopamine (6-OHDA; $100 \mathrm{mg} / \mathrm{kg}$ ) dissolved in $0.9 \% \mathrm{NaCl}$ solution containing $0.1 \%$ ascorbic acid on postnatal days $1-7,14$, 21 , and 28. The control group received equal volumes of solvent at the same time points. The mortality in the sympathectomized group was not increased compared to the control group. Before weaning (four weeks after birth), 7-9 pups were kept with one nursing dam and then the animals were housed five per cage, fed standard laboratory chow ad libitum with free access to drinking water. All rats were used for further experiments at the ages of 20, 40 and 60 postnatal days. The body mass increased with the age and it did not differ between the control and sympathectomized groups: $42.7 \pm 2.8 \mathrm{~g}$ vs. $40.1 \pm 1.1 \mathrm{~g}$ at the age of 20 days, $135.3 \pm 4.1 \mathrm{~g}$ vs. $128.8 \pm 1.8 \mathrm{~g}$ at the age of 40 days and $231.1 \pm 7.9 \mathrm{~g}$ vs. $228 \pm 5.4 \mathrm{~g}$ at the age of 60 days $(\mathrm{n}=10)$, respectively.

\section{Contraction experiments}

Animals were anesthetized with intraperitoneal injection of urethane $(1.5 \mathrm{~g} / \mathrm{kg}$ body weight $) 10 \mathrm{~min}$ after having received heparin $(500 \mathrm{U}$, i.p.) and their hearts were quickly excised. The papillary muscles were dissected from the right or the left ventricles and placed in an experimental chamber with Tyrode solution, where they were attached to an isometric force transducer F30 (Hugo Sachs, Germany). The resting tension was set so that the developed twitch tension reached $90-95 \%$ of maximum at stimulation frequency of $1 \mathrm{~Hz}$. Doublechamber stimulation (stimulator Pulsemaster A300, WPI, USA) was used. The square-wave voltage pulses had duration of $1 \mathrm{~ms}$ and amplitude $\geq 50 \%$ above threshold. Data were recorded using the data acquisition system DiSys (Merlin, Czech Republic). The preparation was perfused with $36{ }^{\circ} \mathrm{C}$ warm, oxygenated solution at a constant flow rate $(6-10 \mathrm{ml} / \mathrm{min})$. After a stabilization period (more than $30 \mathrm{~min}$ ), steady-state contractions at various stimulation frequencies $(3,2,1,0.5,0.3,0.2$ and $0.1 \mathrm{~Hz}$ ) were recorded. Contractions were measured in arbitrary units (a.u.). Time course of contraction was characterized using time-to-peak (time from resting tension to the peak of contraction, TTP) and halfmaximal relaxation time $(\mathrm{R} / 2)$ parameters. The resting tension was taken as zero.

\section{Extraction of norepinephrine and NPY}

Rats were anaesthetized with urethane (see above) and the hearts were rapidly excised, rinsed with ice-cold saline and freed of connective tissue and fat. Immediately after dissection of free walls of both ventricles, the tissues were frozen on dry ice. The NPYlike material was extracted from pulverized heart compartments by boiling in 10 volumes of $0.1 \mathrm{~mol} / 1$ acetic acid for $15 \mathrm{~min}$, rapid cooling on ice and homogenization for $30 \mathrm{~s}$ using an Ultra-Turrax homogenizer. The homogenates were centrifuged 
(10,000 g, $\left.4{ }^{\circ} \mathrm{C}, 20 \mathrm{~min}\right)$; the supernatants were neutralized with $1 \mathrm{~mol} / \mathrm{l}$ Tris-base and centrifuged again $\left(5,000 \mathrm{~g}, 4{ }^{\circ} \mathrm{C}, 10 \mathrm{~min}\right)$. The supernatants were stored at $-70{ }^{\circ} \mathrm{C}$ until radioimmunoassay (RIA) for NPYimmunoreactivity measurements.

Norepinephrine was extracted from the heart ventricles by homogenization in 10 volumes of $0.4 \mathrm{~mol} / 1$ $\mathrm{HClO}_{4}$ and subsequent centrifugation $\left(10,000 \mathrm{~g}, 4{ }^{\circ} \mathrm{C}\right.$, $20 \mathrm{~min}$ ). Supernatants were diluted 1:10 with distilled water and stored at $-70{ }^{\circ} \mathrm{C}$ until RIA. NPY and norepinephrine concentrations were assayed in tissue extracts by RIA using commercial kits (Phoenix Pharmaceuticals, CA, USA and IBL Hamburg, FRG).

\section{Solutions and chemicals}

The composition of the Tyrode solution was following (in mmol/l): $\mathrm{NaCl} 137, \mathrm{KCl} 4.5, \mathrm{MgCl}_{2}$ 1, $\mathrm{CaCl}_{2}$ 2, glucose 10, Hepes 5; $\mathrm{pH}$ was adjusted to 7.4 with $\mathrm{NaOH}$. Tyramine hydrochloride, propranolol hydrochloride, 6-hydroxydopamine hydrobromide (6-OHDA) and other chemicals were from Sigma (St. Louis, MO, USA) or Lachema (Brno, Czech Republic) if not stated otherwise. All chemicals were of analytical grade.

\section{Data analysis}

Results are presented as means \pm SEM. Statistical differences were tested by unpaired two-tailed Student's t-test or by analysis of variance (ANOVA) followed by post hoc Fisher's Least Significant Difference test, using software package STATISTICA $\mathrm{Cz}$, version 7 (StatSoft, Inc., 2004). Normality of populations and homogeneity of variances were tested before each ANOVA. The results were considered significantly different when $\mathrm{p}<0.05$.

\section{Results}

\section{Chemical sympathectomy}

To verify the effectivity of the chemical sympathectomy, norepinephrine concentrations and contractile responsiveness of papillary muscles to tyramine and propranolol were determined in the left and right ventricles. As shown in Figure 1, the absolute values of norepinephrine in control rats did not change with the age of animals. Concentrations of norepinephrine expressed in $\mathrm{ng} / \mathrm{g}$ tissue wet weight varied between $628 \pm 81$ (at the age of 20 days) and $533 \pm 51$ (at the age of 60 days) in the right ventricle, $458 \pm 54$ (at the age of 20 days) and $398 \pm 24$ (at the age of 60 days) in the

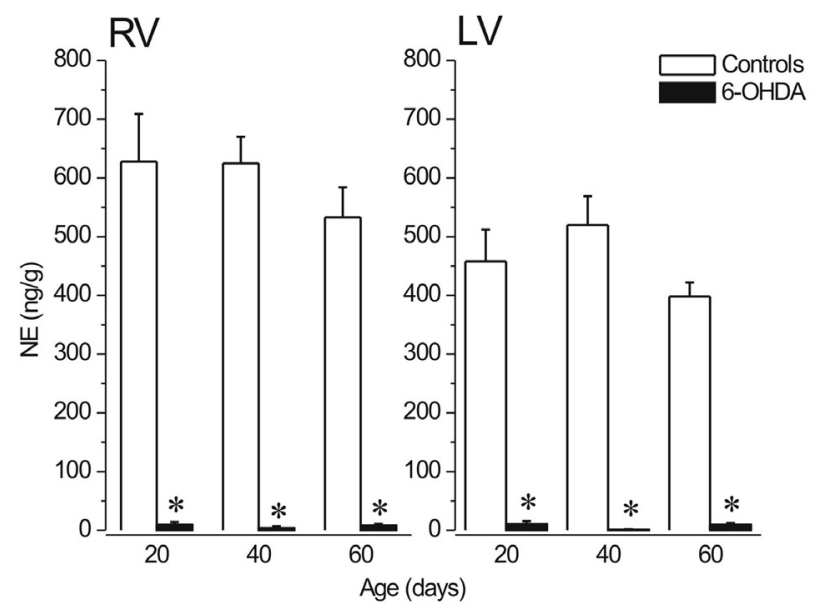

Fig. 1. Norepinephrine (NE) concentrations in the free walls of the right (RV) and left (LV) ventricles of 20-, 40-, and 60-day-old control and sympathectomized (6-OHDA) rats. Data are expressed in $\mathrm{ng} / \mathrm{g}$ tissue wet weight as mean \pm S.E.M., $\mathrm{n}=8$ per group and age category, $* \mathrm{p}<0.01$, compared to the respective control value.

left ventricle. In sympathectomized rats, norepinephrine concentrations reached maximally $9.42 \pm 4.7 \mathrm{ng} / \mathrm{g}$ in the right ventricle and $10.53 \pm 5 \mathrm{ng} / \mathrm{g}$ in the left ventricle at the age of 20 days. The values of norepinephrine concentrations in denervated rats did not change significantly during the whole experiment (Fig. 1).

Tyramine stimulates norepinephrine release from the sympathetic nerve terminals (Sulzer et al. 2005). In control rats, administration of tyramine significantly increased the contraction force $(\mathrm{CF})$ of papillary muscles from both ventricles independent of age. The maximal increase in $\mathrm{CF}$ of the right ventricular papillary muscles in comparison with tyramine-free solution was observed at tyramine concentration of $10^{-4} \mathrm{~mol} / \mathrm{l}$ in 40-day-old rats $(162 \pm 8.4 \%)$ and at tyramine concentration of $10^{-5} \mathrm{~mol} / \mathrm{l}$ in 20 - and 60-day-old rats $(140 \pm 11.6 \%$ and $151 \pm 8.1 \%$, respectively, Fig. 2A). In the left ventricular papillary muscle, the maximum positive inotropic effect of tyramine was found at concentration of $10^{-5} \mathrm{~mol} / 1$ in all age categories, i.e. compared to tyramine-free solution $142 \pm 5.8 \%, 160 \pm 4.3 \%$ and $153 \pm 4.5 \%$ in $20-, 40-$ and 60-day-old rats, respectively (Fig. 2B). The values of CF of the right and left ventricular papillary muscles after application of $\beta$-adrenergic blocker propranolol $\left(10^{-4}\right.$ $\mathrm{mol} / \mathrm{l})$ on top of tyramine $\left(10^{-4} \mathrm{~mol} / \mathrm{l}\right)$ were not significantly different from values in tyramine-free solution in any age group (Fig. 2A, 2B). In contrast, both right and left ventricle papillary muscles of sympathectomized rats were insensitive to both tyramine and propranolol in all age groups (Fig. 2C, 2D). 

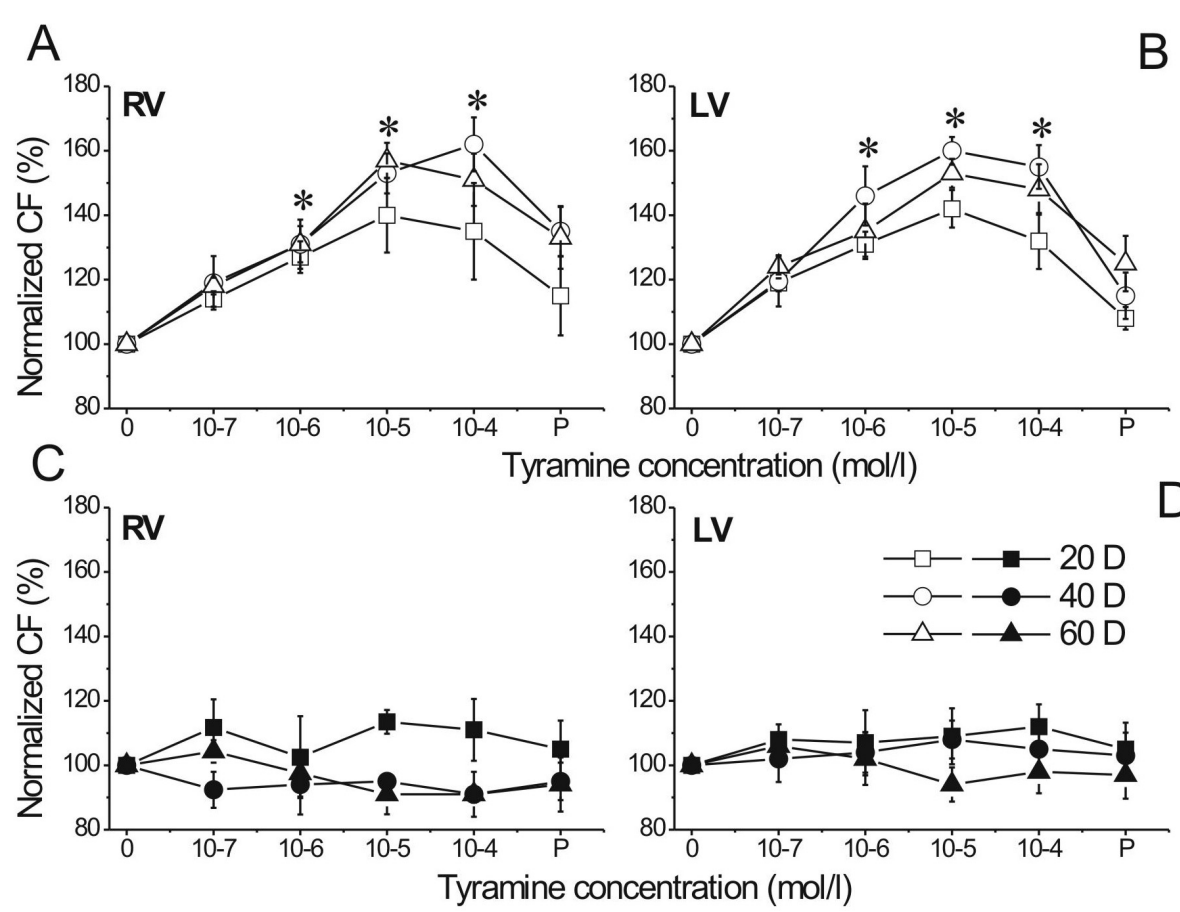

Fig. 2. The effect of tyramine and propranolol on contraction force of the control and sympathectomized rats. A, B. Contraction force (CF) of papillary muscles from the right (RV) and left ventricles (LV) in control rats $(n=6)$. C, D. Contraction force (CF) of papillary muscles from the right (RV) and left (LV) ventricles in sympathectomized rats $(n=5)$. Values were normalized to the CF in tyramine-free solution (taken as $100 \%$ ). Stimulation frequency was $1 \mathrm{~Hz}$. $\mathrm{D}=$ age in days. $\mathrm{P}=$ administration of propranolol $\left(10^{-4} \mathrm{~mol} / \mathrm{l}\right)$ on top of tyramine $\left(10^{-4}\right.$ $\mathrm{mol} / \mathrm{l}) . * \mathrm{p}<0.01$, compared to the value in tyramine-free solution.

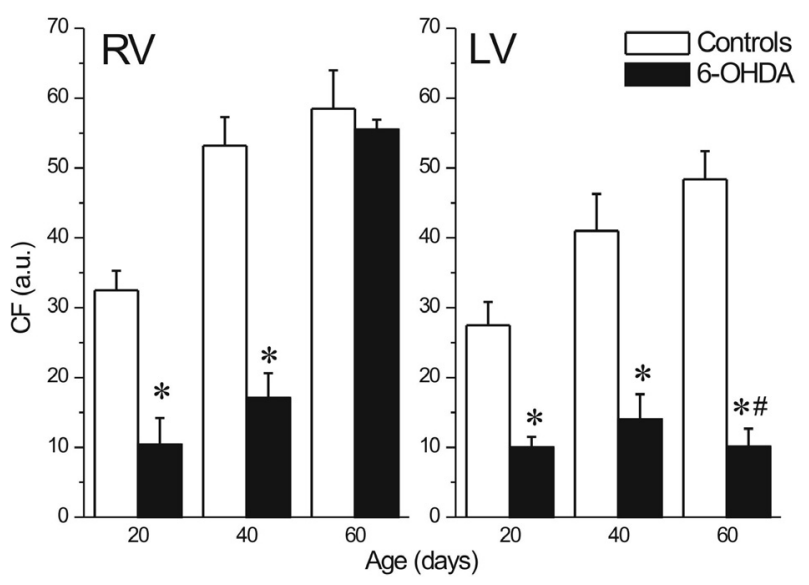

Fig. 3. The contraction force of the control and sympathectomized (6-OHDA) rats. Left panel: Contraction force (CF) of papillary muscles from the right ventricles (RV) in control $(n=6)$ and sympathectomized rats $(n=5)$. Right panel: Contraction force (CF) of papillary muscles from the (LV) ventricles in control $(n=6)$ and sympathectomized $(n=5)$ rats. Stimulation frequency was $1 \mathrm{~Hz}$. * $\mathrm{p}<0.01$, compared to the respective control value, ${ }^{\#} \mathrm{P}<0.01$, compared to the respective value in the right ventricle.

\section{Contraction experiments}

Chemical sympathectomy significantly decreased the contraction force of the papillary muscle in 20- and 40-day-old rats in the right ventricle and in all age categories in the left ventricle (Fig. 3). CF of the intact rats increased with age in both ventricles and it was $32.5 \pm 2.8$ a.u., $53.2 \pm 4.1$ a.u. and $58.5 \pm 5.5$ a.u. at stimulation frequency of $1 \mathrm{~Hz}$ in the right ventricle at the age of 20, 40 and 60 days, respectively (Fig. 3, the left panel). In the left ventricle of intact rats, $\mathrm{CF}$ at $1 \mathrm{~Hz}$ was $27.5 \pm 3.3$ a.u., $41 \pm 5.3$ a.u. and $48.4 \pm 4.04$ a.u. at the ages of 20, 40 and 60 days, respectively (Fig. 3, the right panel). In the right ventricle of denervated rats, $\mathrm{CF}$ was significantly lower at the ages of 20 and 40 days being $10.4 \pm 3.8$ a.u. and $17.1 \pm 3.5$ a.u. at $1 \mathrm{~Hz}$, respectively. At day 60, however, this reduction disappeared and $\mathrm{CF}$ of the right papillary muscle was comparable to control (55 \pm 1.4 a.u. at $1 \mathrm{~Hz}$, Fig. 3, the left panel). In the left ventricle of sympathectomized rats, values of $\mathrm{CF}$ were significantly lower compared to control regardless of the age, varying from $10 \pm 1.5$ a.u. in 20-day-old rats to $14 \pm 3.6$ a.u. in 40-day-old ones (Fig. 3, the right panel). The effect of the chemical sympathectomy on CF was well expressed at all stimulation frequencies tested (0.1-3 $\mathrm{Hz}$ ), i.e. CF of papillary muscles in denervated rats was always significantly lower than in control rats except the right ventricle papillary muscles at the age of 60 days (Fig. 4).

In both control and denervated rats, time to peak of contraction (TTP) shortened with increasing frequency of stimulation in all age groups. Neither chemical sympathectomy nor age of animals affected TTP. Similarly, half-maximal relaxation time $(R / 2)$ shortened with increasing frequency of stimulation and there was no difference between the intact and sympathectomized rats at any age (data at the stimulation frequency of $1 \mathrm{~Hz}$ in Table 1). 
A
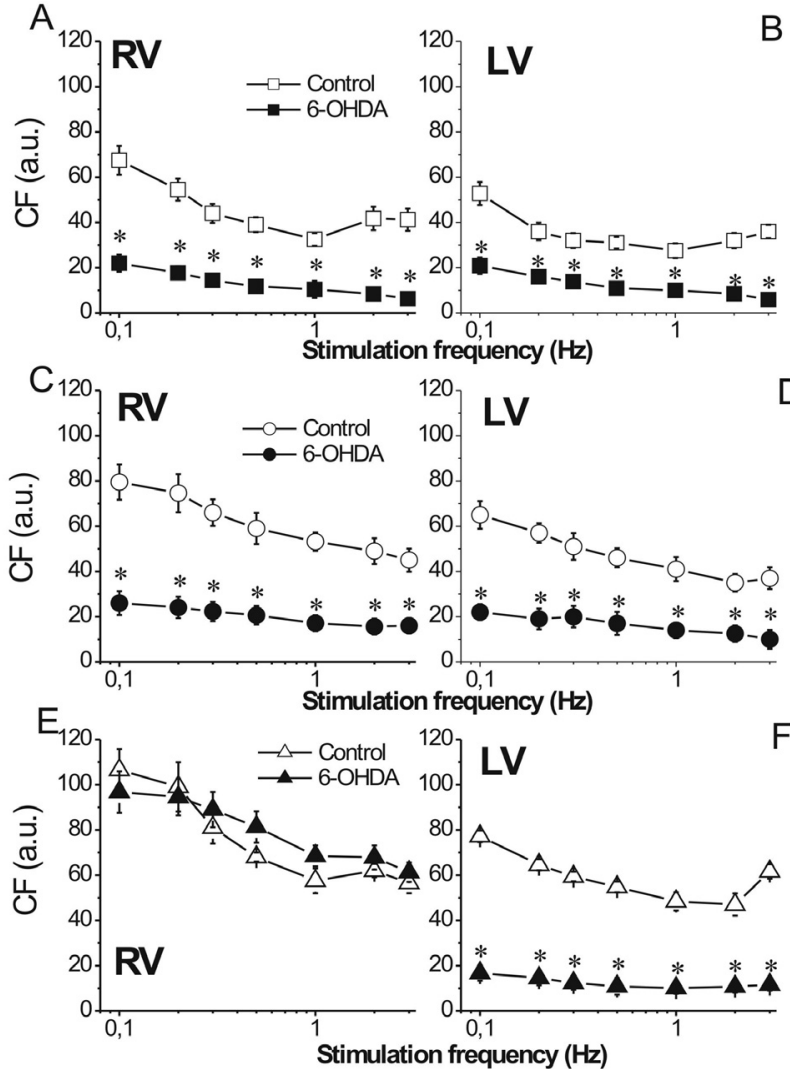

Fig. 4. The contraction force of the control and sympathectomized rats. A, B. Contraction force (CF) of papillary muscles from the right (RV) and left ventricles (LV) in 20-day-old control $(n=6)$ and sympathectomized $(n=5)$ rats. C, D. Contraction force (CF) of papillary muscles from the right (RV) and left (LV) ventricles in 40-day-old control $(n=6)$ and sympathectomized $(n=5)$ rats. E, F. Contraction force (CF) of papillary muscles from the right (RV) and left ventricles (LV) in 60 -day-old control $(n=6)$ and sympathectomized $(n=5)$ rats. $* \mathrm{P}<0.01$, compared to the respective control value.

\section{Neuropeptide Y concentrations}

To elucidate the impact of chemical denervation on cardiac sympathetic innervation, we measured the ventricular concentrations of NPY that is in addition to norepinephrine located in sympathetic postganglionic fibers. The values of NPY concentrations in controls were not influenced by age and they showed no difference between the right and the left ventricles (Fig. 5). The effect of sympathetic denervation on NPY concentrations was different in the right ventricle compared to the left one. In the right ventricle, the peptide concentrations were significantly lower compared to their respective controls at the ages of 20 and 40 days. At age of 60 days, however, NPY concentrations were markedly increased and were no longer significantly different from the agematched controls (Fig. 5, upper panel). In the left ventricle, NPY concentrations remained significantly lower than their respective controls in all age categories

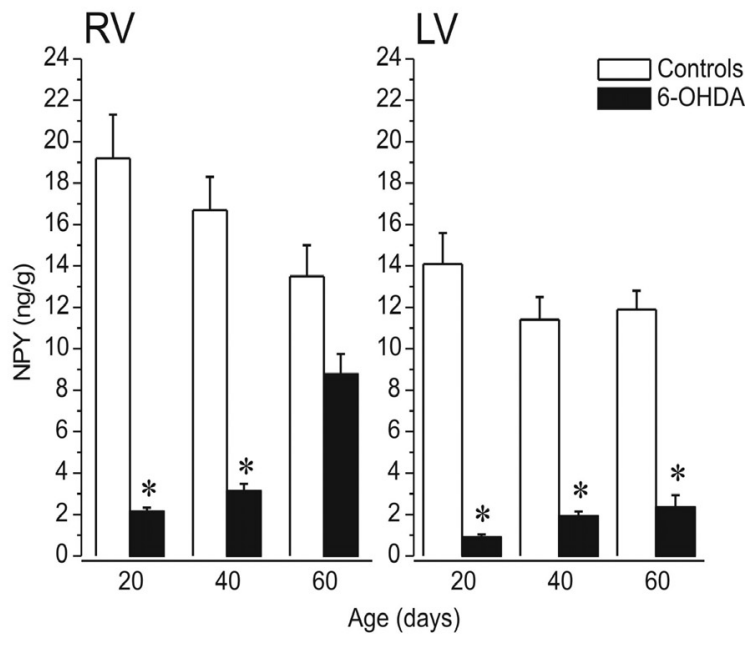

$\mathrm{NE}(\mathrm{ng} / \mathrm{g})$

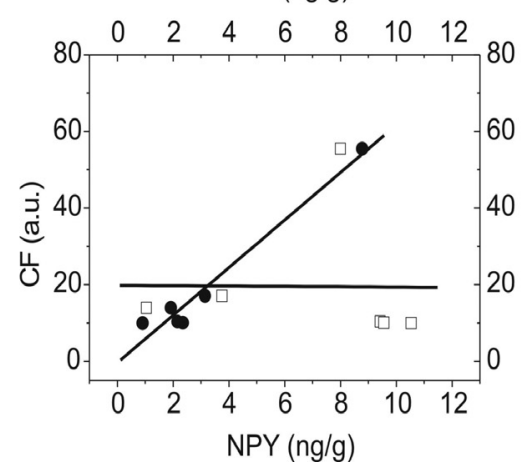

Fig. 5. Upper panel, neuropeptide $Y$ (NPY) concentrations in the free walls of the right (RV) and left (LV) ventricles of 20-, 40-, and 60-day-old control and sympathectomized (6-OHDA) rats. Data are expressed in $\mathrm{ng} / \mathrm{g}$ tissue wet weight as mean \pm S.E.M., $\mathrm{n}=8$ per group and age category, $* \mathrm{P}<0.01$, compared to the respective control value. Lower panel, correlation of norepinephrine (NE, open symbols) and NPY (closed symbols) concentrations with contraction force (CF) in denervated rats.

(Fig. 5, upper panel). Concentrations of NPY showed a good correlation with CF (Fig. 5, lower panel, $\mathrm{R}=0.986$ ) whereas no correlation was found for norepinephrine concentrations and $\mathrm{CF}(\mathrm{R}=0.0005)$.

\section{Discussion}

In our study, the administration of 6-OHDA induced an almost complete reduction in norepinephrine concentrations in both right and left ventricles at all time points studied (20, 40 and 60 days of postnatal life). Tyramine, a stimulator of norepinephrine release from sympathetic nerve terminals, was not able to increase contraction of papillary muscles from sympathectomized rats. These data indicate that the chemical sympathectomy was effective. The contractility was influenced by the chemical sympathectomy differentially in the left and the right ventricle. In the left ventricle, the 
Table 1. Time to peak of contraction (TTP) and half-maximal relaxation time (R/2) in control and sympathectomized rats at the stimulation frequency of $1 \mathrm{~Hz}$.

\begin{tabular}{|c|c|c|c|c|c|c|}
\hline & \multicolumn{3}{|c|}{ Control rats $(n=6)$} & \multicolumn{3}{|c|}{ Sympathectomized rats $(n=5)$} \\
\hline & \multicolumn{6}{|c|}{ TTP (ms) } \\
\hline & 20D & 40D & 60D & 20D & 40D & 60D \\
\hline$R V$ & $55 \pm 7.6$ & $57 \pm 6.1$ & $53 \pm 5.5$ & $54 \pm 5.1$ & $51 \pm 5.9$ & $60 \pm 4$ \\
\hline \multirow[t]{2}{*}{$L V$} & $58 \pm 6.7$ & $59 \pm 8.3$ & $55 \pm 3.7$ & $59 \pm 4.9$ & $55 \pm 6.1$ & $57 \pm 1.2$ \\
\hline & \multicolumn{6}{|c|}{$\mathrm{R} / 2(\mathrm{~ms})$} \\
\hline$R V$ & $46 \pm 5.9$ & $43 \pm 3.8$ & $41 \pm 4.7$ & $39 \pm 2.7$ & $37 \pm 3.8$ & $40 \pm 3.3$ \\
\hline$L V$ & $48 \pm 3.2$ & $45 \pm 4.8$ & $40 \pm 2.1$ & $44 \pm 3.8$ & $42 \pm 5.3$ & $47 \pm 0.7$ \\
\hline
\end{tabular}

$\mathrm{RV}$ - the right ventricle, $\mathrm{LV}$ - the left ventricle, $\mathrm{D}=$ age in days.

contraction was substantially depressed at all time points. In the right ventricle, in contrast to the development of contraction force in the left ventricle and to norepinephrine levels, the contraction was significantly reduced only at 20 and 40 days of postnatal life. At 60 days of postnatal life, the contraction in the right ventricle recovered and was no longer different from controls. This differential development of contractility cannot be explained on the basis of norepinephrine tissue concentrations that remained low in both ventricles of sympathectomized rats throughout the whole experiment. The other neurotransmitter present in sympathetic nerves (Zukowska et al. 2003), NPY, however, showed a different developmental pattern that exactly matched the development of contractility: permanent suppression in the left ventricle vs. transient suppression (at 20 and 40 days) with a recovery (at 60 days) in the right ventricle. This suggests that from the two transmitters stored in sympathetic nerves, NPY, but not norepinephrine, controls the development of contractility. Nevertheless, some contribution of norepinephrine to the development of contractility in the early phases of development cannot be excluded. The mechanisms, by which NPY might increase the contractility, are still questionable and were not addressed in this study. Based on recent reports showing that NPY contributes to the developmental increase in ICaL, both in vitro (Protas and Robinson 1999) and in vivo (Protas et al. 2003), it may be suggested that ICaL is the likely target of NPY action. Nevertheless, other contributing mechanisms such as enhanced synthesis and attenuated degradation of contractile proteins (Nicholl et al. 2002) may also be involved.

Another important question is what is the putative source of NPY in hearts of sympathectomized rats. Repeated administration of 6-OHDA to neonatal rats causes permanent destruction of the sympathetic neurons by a two-step process: after its uptake into the sympathetic postganglionic fibers and nerve cell bodies by norepinephrine transporter, 6-OHDA undergoes a series of chemical transformations that lead to reactive oxygen species generation followed by the loss of the cell membrane integrity and the cell death (Picklo 1997). However, beside localization in the sympathetic postganglionic fibers (together with norepinephrine), NPY was also identified in the nonadrenergic intrinsic neurons that are located on the base of the heart above the atrioventricular groove in four distinct groups (Pardini et al. 1987). These intrinsic neurons send their processes to adjacent neurons within the intracardiac ganglia, small intensely fluorescent cells, and intramyocardial resistance vessels (Corr et al. 1990, Slavíková et al. 2003). In addition, NPY was also found extraneuronally in platelets and endocardium (Zukowska-Grojec et al. 1993, Jacques et al. 2006). The impact of sympathectomy on the myocardial NPY levels might differ depending on the method used. It has been reported that surgical bilateral sympathectomy of the adult rat heart produced similar reductions in concentrations of norepinephrine and NPY in the ventricular tissue (MacCarrone and Jarrott 1987). In contrast, chemical sympathectomy achieved by longterm guanethidine administration to neonatal rats led to differential reductions of norepinephrine and NPY levels in the rat heart: whereas norepinephrine was nearly totally depleted from the myocardium of sympathectomized rats at 6 weeks and 4 months of age, reaching $1-10 \%$ of concentrations in untreated animals, levels of NPY were decreased by $46-66 \%$ only (Corr et al. 1990). In our study, the impact of repeated administration of 6-OHDA on the ventricular NPY levels 
seemed to be more profound at the ages of 20 and 40 days than that reported for guanethidine sympathectomy, since NPY concentrations were reduced by $81-94 \%$ compared to control values. However, at the age of 60 days, right ventricular NPY concentrations were not significantly different from the control values, whereas NPY levels remained low in the sympathectomized left ventricles. It is thus possible that NPY in the right ventricle recovered from the intrinsic neurons containing NPY that reinnervated relatively thin wall of the right ventricle and that similar reinnervation of much greater mass of the left ventricle could be substantially delayed.

Mammalian heart is known to undergo a significant postnatal development of morphological and functional parameters. Lacking T-tubules, lower density of diads and gap junctions, less cardiomyocyte size, poorly developed sarcoplasmic reticulum and its lower sensitivity to calcium ions are characteristic for immature rat myocardium (Vornanen 1996). The postnatal development of rat cardiomyocytes also includes changes in ion channels expression and function (Wetzel and Klitzner 1996). Because of poor sarcoplasmic reticulum and T-tubules in neonatal heart, $\mathrm{Ca}^{2+}$-induced $\mathrm{Ca}^{2+}$ release (CICR) does not play a key role in excitationcontraction coupling, hence the contraction in the developing heart is dependent mainly on transsarcolemmal $\mathrm{Ca}^{2+}$ influx for contraction generation via $\mathrm{ICaL}$ and the reverse mode of $\mathrm{Na}^{+}-\mathrm{Ca}^{2+}$ exchanger. CICR from the sarcoplasmic reticulum becomes dominant in cardiac excitation-contraction coupling at the end of third week of postnatal life (Escobar et al. 2004). Postnatal maturation of the rat heart is followed by an increase in contraction force of the multicellular preparation that continues till adulthood even if morphological development of the heart is over (Capasso et al. 1982, Leblanc et al. 1998). Similarly, in our experiments performed on papillary muscles of control rats, the contraction force increased with age to achieve the maximal value at the age of 60 days in both ventricles.

\section{Limitations of the study}

The contractility was studied using papillary muscles from both ventricles. Papillary muscles represent endocardial portion of the ventricular wall. Given the fact that the endocardial, midmyocardial and epicardial ventricular layers show substantial electrical and contractile differences (Liu et al. 1993, Cordeiro et al. 2004) as well as differential responses to various stimuli (McCrossan et al. 2004), it is possible that the contractile development in midmyocardial and epicardial layers is different in some aspects. Since the NPY concentrations and contractions in sympathectomized rats show good correlation, a relationship between these two parameters may be suggested. The causality of this relationship, however, remains unclear and new experiments with NPY antagonists and/or antibodies will be necessary.

\section{Conclusions}

The intact sympathetic innervation plays an important role in the development of cardiac contractility. The response of the left ventricle and of the right ventricle to the chemical sympathectomy is different: whereas the left ventricle showed a sustained reduction in contractile performance, in the right ventricle a recovery of contractility was detected. NPY is likely to contribute significantly to the postnatal development of contractility.

\section{Conflict of Interest}

There is no conflict of interest.

\section{Acknowledgements}

The present study was supported by the Research project MSM 0021620819: Replacement of and Support to Some Vital Organs awarded by the Ministry of Education, Youth and Sports of the Czech Republic and by the Grant Agency of the Czech Republic, grant No. 305/04/0144. We thank Renata Št’astná and Ivana Kušková for excellent technical assistance.

\section{References}

CAPASSO JM, REMILY RM, SONNENBLICK EH: Alteration in mechanical properties of rat papillary muscle during maturation. Am J Physiol 242: H359-H364, 1982.

CORDEIRO JM, GREENE L, HEILMANN C, ANTZELEVITCH D, ANTZELEVITCH C: Transmural heterogeneity of calcium activity and mechanical function in the canine left ventricle. Am J Physiol 286: H1471-H1479, 2004. 
CORR LA, ABERDEEN JA, MILNER P, LINCOLN J, BURNSTOCK G: Sympathetic and nonsympathetic neuropeptide Y content in the rat myocardium and coronary arteries. Circ Res 66: 1602-1609, 1990.

ESCOBAR AL, RIBEIRO-COSTA R, VILLALBA-GALEA C, ZOGHBI ME, PEREZ CG, MEJIA-ALVAREZ R: Developmental changes of intracellular $\mathrm{Ca}^{2+}$ transients in beating rat hearts. Am J Physiol 256: H971-H978, 2004.

JACQUES D, SADER S, PERREAULT C, ABDEL-SAMAD D, PROVOST C: Roles of nuclear NPY and NPY receptors in the regulation of the endocardial endothelium and heart function. Can J Physiol Pharmacol 84: 695-705, 2006.

KAMEYAMA M, HESCHELER J, HOFMANN F, TRAUTWEIN W: Modulation of Ca current during the phosphorylation cycle in the guinea pig heart. Pflugers Arch 407: 123-128, 1986.

LEBLANC N, CHARTIER D, GOSSELIN H, ROULEAU JL: Age and gender differences in excitation-contraction coupling of the rat ventricle. J Physiol Lond 511: 533-548, 1998.

LIU DW, GINTANT GA, ANTZELEVITCH C: Ionic bases for electrophysiological distinctions among epicardial, midmyocardial, and endocardial myocytes from the free wall of the canine left ventricle. Circ Res 72: 671-687, 1993.

MACCARRONE C, JARROTT B: Differential effects of surgical sympathectomy on rat heart concentrations of neuropeptide Y-immunoreactivity and noradrenaline. J Auton Nerv Syst 21:101-107, 1987.

MAKI T, GRUVER EJ, DAVIDOFF AJ, IZZO N, TOUPIN D, COLUCCI W, MARKS AR, MARSH JD: Regulation of calcium channel expression in neonatal myocytes by catecholamines. J Clin Invest 97: 656-663, 1996.

MARTIN AF, BALL K, GAO LZ, KUMAR P, SOLARO RJ: Identification and functional significance of troponin I isoforms in neonatal rat heart myofibrils. Circ Res 69: 1244-1252, 1991.

MCAULIFFE JJ, GAO LZ, SOLARO RJ: Changes in myofibrillar activation and troponin $\mathrm{C} \mathrm{Ca}^{2+}$ binding associated with troponin $\mathrm{T}$ isoform switching in developing rabbit heart. Circ Res 66: 1204-1216, 1990.

MCCROSSAN ZA, BILLETER R, WHITE E: Transmural changes in size, contractile and electrical properties of SHR left ventricular myocytes during compensated hypertrophy. Cardiovasc Res 63: 283-292, 2004.

NICHOLL SM, BELL D, SPIERS J, MCDERMOTT BJ: Neuropeptide Y Y receptor regulates protein turnover and constitutive gene expression in hypertrophying cardiomyocytes. Eur J Pharmacol 441: 23-34, 2002.

OGAWA S, BARNETT JV, SEN L, GALPER JB, SMITH TW, MARCH JD: Direct contact between sympathetic neurons and rat cardiac myocytes in vitro increases expression of functional calcium channels. $J$ Clin Invest $\mathbf{8 9}$ : 1085-1093, 1992.

PARDINI BJ, PATEL KP, SCHMID PG, LUND DD: Location, distribution and projections of intracardiac ganglion cells in the rat. J Auton Nerv Syst 20: 91-101, 1987.

PICKLO MJ: Methods of sympathetic degenaration and alteration. J Auton Nerv Syst 62: 111-125, 1997.

PROTAS L, ROBINSON RB: Neuropeptide Y contributes to innervation-dependent increase in I (Ca, L) via ventricular Y2 receptors. Am J Physiol 277: H940-H946, 1999.

PROTAS L, BARBUTI A, QU J, RYBIN VO, PALMITER RD, STEINBERG SF, ROBINSON RB: Neuropeptide Y is an essential in vivo developmental regulator of cardiac ICa,L. Circ Res 93: 972-979, 2003.

ROBINSON RB: Autonomic receptor-effector coupling during post-natal development. Cardiovasc Res 31: E68-E76, 1996.

SLAVÍKOVÁ J, KUNCOVÁ J, REISCHIG J, DVOŘÁKOVÁ M: Catecholaminergic neurons in the rat intrinsic cardiac nervous system. Neurochem Res 28: 593-598, 2003.

SULZER D, SONDERS MS, POULSEN NW, GALLI A: Mechanisms of neurotransmitter release by amphetamines: a review. Prog Neurobiol 75: 406-433, 2005.

TANAKA H, SHIGENOBU K: Effect of ryanodine on neonatal and adult rat heart: developmental increase in sarcoplasmic reticulum function. J Mol Cell Cardiol 21: 1305-1313, 1989.

VORNANEN M: Excitation-contraction coupling of the developing rat heart. Mol Cell Biochem 163-164: 5-11, 1996.

WETZEL GT, KLITZNER TS: Developmental cardiac electrophysiology. Recent advances in cellular physiology. Cardiovasc Res 31: E52-E60, 1996. 
WIBO M, BRAVO G, GODFRAIND T: Postnatal maturation of excitation-contraction coupling in rat ventricle in relation to the subcellular localization and surface density of 1,4-dihydropyridine and ryanodine receptors. Circ Res 68: 662-673, 1991.

ZUKOWSKA Z, PONS J, LEE EW, LI L: Neuropeptide Y: a new mediator linking sympathetic nerves, blood vessels and immune system? Can J Physiol Pharmacol 81: 89-94, 2003.

ZUKOWSKA-GROJEC Z, GOLCZYNSKA M, SHEN GH, TORRES-DUARTE A, HAASS M, WAHLESTEDT C, MYERS AK: Modulation of vascular function by neuropeptide $Y$ during development of hypertension in spontaneously hypertensive rats. Pediatr Nephrol 7: 845-852, 1993. 